\title{
Initiation of Somatostatin analogues for neuroendocrine tumor patients: a cost- effectiveness analysis
}

Sheila D. Rustgi ${ }^{1,2}$, Aaron Oh², Jeong Yun Yang ${ }^{3}$, Dasol Kang ${ }^{4}$, Edward Wolin ${ }^{5}$, Chung Y. Kong ${ }^{6}$, Chin Hur ${ }^{2}$ and Michelle K. Kim ${ }^{1 *}$

\begin{abstract}
Background \& Aims: Gastroenteropancreatic neuroendocrine tumors (GEP-NETs) are heterogeneous neoplasms. Although some have a relatively benign and indolent natural history, others can be aggressive and ultimately fatal. Somatostatin analogues (SSAs) improve both quality of life and survival for these patients once they develop metastatic disease. However, these drugs are costly and their cost-effectiveness is not known.
\end{abstract}

Methods: A decision-analytic model was developed and analyzed to compare two treatment strategies for patients with Stage IV GEP-NETs. The first strategy had all patients start SSA immediately while the second strategy waited, reserving SSA initiation until the patient showed signs of progression. Sensitivity analysis was performed to explore model parameter uncertainty.

Results: Our model of patients age 60 with metastatic GEP-NETs suggests empiric initiation of SSA led to an increase 0.62 unadjusted life-years and incremental increase in quality-adjusted life years (QALYS) of 0.44 . The incremental costs were $\$ 388,966$ per QALY and not cost-effective at a willingness-to-pay threshold of $\$ 100,000$. Death was attributed to GEP-NETs for $94.1 \%$ of patients in the SSA arm vs. 94.9\% of patients in the DELAY SSA arm. Sensitivity analysis found that the model was most sensitive to costs of SSAs. Using probabilistic sensitivity analysis, the SSA strategy was only cost-effective $1.4 \%$ of the time at a WTP threshold of $\$ 100,000$ per QALY.

Conclusions: Our modeling study finds it is not cost-effective to initiate SSAs at time of presentation for patients with metastatic GEP-NETs. Further clinical studies are needed to identify the optimal timing to initiate these drugs.

Keywords: Neuroendocrine tumors, Cost-effectiveness analysis, Somatostatin analogues, Carcinoid, Peptide receptor radionuclide therapy

\footnotetext{
* Correspondence: michelle.kim@mountsinai.org

${ }^{1}$ Henry D. Janowitz Division of Gastroenterology, Mount Sinai Health System,

Icahn School of Medicine at Mount Sinai, One Gustave L. Levy Place, Box

1118, New York, NY 10029-6574, USA

Full list of author information is available at the end of the article
}

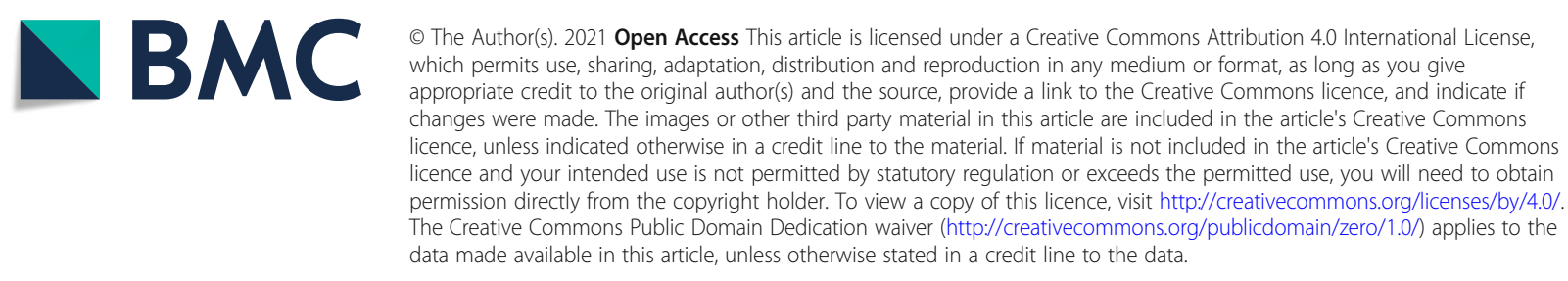




\section{Background}

Nearly 200,000 Americans have gastroenteropancreatic neuroendocrine tumors (GEP-NETs), with a higher prevalence than esophageal, gastric, and pancreatic cancers combined [1]. Studies show the incidence is rising over the past 30 years, especially in older adults [2-5]. Nearly half of GEP-NETs patients present with late stage disease from the midgut or pancreas, with 5-year survival ranging from 26 to $75 \%$ and substantial associated cancer-related morbidity [2, 6-8]. Treatment is expensive, with estimated costs per patient more than twice that of colon cancer [9-12] in part due to continuous therapy with somatostatin analogues (SSAs), a costly monthly injection [13-18].

For these patients, SSAs are an important treatment that control disease symptoms [19] as well as tumor growth [20-22]. More recently, two randomized placebo-controlled trials (RCTs), the Controlled Study of Lanreotide Antiproliferative Response in Neuroendocrine Tumors (CLARINET) and Placebo-Controlled, Double-Blind, Prospective, Randomized Study on the Effect of Octreotide LAR in the Control of Tumor Growth in Patients With Metastatic Neuroendocrine Midgut Tumors (PROMID) showed a delay in progression of disease for patients treated empirically with SSAs [13, 23-25]. However, consensus guidelines remain unclear as to whether patients should start
SSA immediately when diagnosed with metastatic disease, or delay SSA until time of tumor progression $[26,27]$. This gap in knowledge leads to physician uncertainty and heterogeneous practice patterns, as well as considerable confusion to patients as to the right course of action to pursue.

The aim of this study is to evaluate the costeffectiveness of initiating SSAs for patients with metastatic GEP-NETs at time of diagnosis versus at time of disease progression. Modeling is a comparative effectiveness method that allows us to incorporate clinical factors to evaluate the cost-effectiveness of SSAs in metastatic GEP-NETs patients. We hypothesized that, because of the costs, starting SSAs at time of diagnosis may ultimately prolong and improve quality of life, but will not be cost-effective.

\section{Methods}

The study population was patients with metastatic GEPNETs [28-34]. The goal of this study was to use decision-analytic modeling to help patients and providers choose when to initiate therapy with SSAs. Institutional review board approval was not required for this study that did not use human participants. The data for the model was obtained from published literature and is cited in Table 1.

Table 1 Model Parameters

\begin{tabular}{|c|c|c|c|}
\hline Parameter & Base-Case Value & Sensitivity Analysis & Source \\
\hline Starting Age & 60 & & 13,23 \\
\hline Dose SSA & $\begin{array}{l}\text { Octreotide LAR } 20 \mathrm{mg} / 28 \text { days } \\
\text { Octreotide } 60 \mathrm{mg} \text { with PRRT }\end{array}$ & & $38-40$ \\
\hline \multicolumn{4}{|l|}{ Costs } \\
\hline Cost SSA & $\$ 4121 /$ month for Octreotide & $\$ 2060-\$ 8242$ & 28 \\
\hline Cost PRRT & $\$ 205,200$ & $\$ 102,600-410,400$ & 31,41 \\
\hline \multicolumn{4}{|l|}{ Complication, Mortality and Progression Estimates } \\
\hline Rate of Complications from SSA & $1 \%$ over 96 weeks & $+/-25 \%$ & 13,23 \\
\hline All cause mortality & CDC Life Tables & & 32 \\
\hline Rate of NET related death, untreated & 18 month median survival & $+/-25 \%$ & 25,33 \\
\hline Rate of NET related death, on SSA & 39 month median survival & $+/-25 \%$ & 25,33 \\
\hline Rate of NET related death, on PRRT & 39 month median survival & $+/-25 \%$ & 37,42 \\
\hline Rate of progression, off SSA & 6 month median & $+/-25 \%$ & 13,23 \\
\hline Rate of progression, on SSA & 14 month median & $+/-25 \%$ & 13,23 \\
\hline Rate of progression after delaying initiation of SSA & 14 month median & $+/-25 \%$ & 24,37 \\
\hline \multicolumn{4}{|l|}{ Utilities } \\
\hline Quality of Life pre SSA & 0.79 & $+/-0.1$ & $34,35,43$ \\
\hline Quality of Life on SSA & 0.79 & $+/-0.1$ & 34,43 \\
\hline Quality of Life with disease progression & 0.72 & $+/-0.1$ & 34 \\
\hline Quality of Life with uncontrolled symptoms & 0.32 & $+/-0.1$ & 36,44 \\
\hline
\end{tabular}

SSA somatostatin analogues; PRRT Peptide Receptor Radionuclide Therapy; NET neuroendocrine tumor 


\section{Model overview}

We developed a Markov-based state-transition model using TreeAge Pro (TreeAge 2020, Williamstown, Massachusetts) to compare initiation of SSAs at the time of diagnosis of stage IV GEP-NETs versus waiting to start SSA until the patient's disease progressed (Fig. 1). The base-case model was based on population characteristics from two prospective RCTs (CLARINET and PROMID) and followed patients from age 60 and cycled monthly until death or age 100 [13, 23-25].

\section{Management strategy}

We simulated and compared two strategies. In the first (SSA), patients were immediately started on SSAs at the time of diagnosis of metastatic GEP-NETs. In the second strategy (DELAY), patients were observed and started on SSAs once their disease progressed. In both strategies, once patients were started on SSAs, if they developed complications from the drug, therapy was discontinued. Alternatively, their disease could progress while on SSA. Once the disease progressed, either on SSA or after stopping SSA due to complications, they were treated with Peptide Receptor Radionuclide Therapy (PRRT). SSA was continued while on PRRT.

\section{Outcomes}

Our outcomes were unadjusted life years gained, incremental costs, quality adjusted life years (QALYs) and the incremental cost-effectiveness ratio (ICER). QALYs are a measure of health which account for both the absolute quantity of survival time adjusted with quality of life.
QALYs were subject to half cycle correction and discounted at a standard rate of $3 \%$ annually. We assessed cost-effectiveness for each treatment strategy by estimating ICERs. The ICERs were calculated on an efficiency frontier. The willingness-to-pay (WTP) threshold to determine cost-effectiveness was $\$ 100,000$ per QALY. The optimal timing of whether to delay or initiate therapy right away was defined as the strategy which yielded the highest number of QALYs while having an ICER less than $\$ 100,000$.

\section{Model inputs and probabilities}

The primary sources of data for model inputs were the two RCTs and the subsequent open label extension studies (Table 1) [13, 23-25]. The starting age for our patient cohort was 60 , based on median ages of 62-63 from the two trials. The cost of octreotide, the drug used in the PROMID trials, was $\$ 4121$ per month [13, 25, 35]. We used octreotide rather than lanreotide based on previous studies suggesting the former is more costeffective [36, 37]. The cost of PRRT was $\$ 51,300$ per cycle for a total of four cycles [38]. A 3\% discount was applied to costs. The costs were adjusted for inflation to 2020 dollars.

The probability of complications was calculated from serious complication rates requiring cessation of drug use in the CLARINET trial, which was approximately $1 \%$.

All-cause mortality rates were derived using the Center for Disease Control life tables [39]. Because GEPNETs related deaths do not contribute significantly to

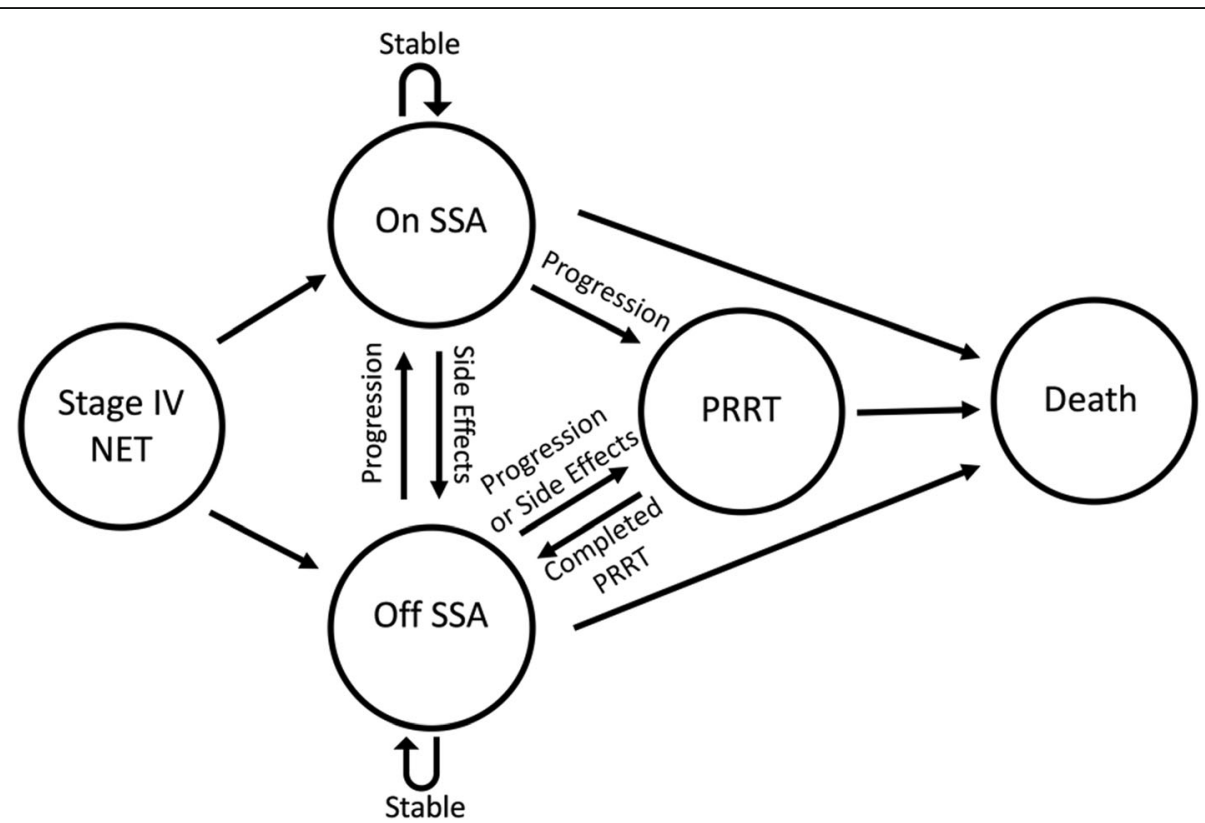

Fig. 1 Model Diagram. The figure is a simplified schematic of the Markov model. Circles represent health states and arrows represent transitions. Acronyms: NET = neuroendocrine tumor; SSA = somatostatin analogues; PRRT = Peptide Receptor Radionuclide Therapy 
the national all-cause mortality rates, the rates were used without adjustment. Rates of GEP-NETs related death both on and off SSA were calculated using survival from Surveillance, Epidemiology and End Results (SEER) studies comparing the pre-SSA era to the post-SSA era [40]. The only new treatment introduced during this time period was SSA. Rates of GEP-NETs related death on PRRT were assumed to be the same as rates of GEPNETs related death on SSA.

Rates of progression of disease in different scenarios were extrapolated from the two RCTs. Progression rates both on and off SSA were used from the PROMID trial and the extension study. Rates of progression for patients who started SSA after delay of initiation were calculated using the placebo-lanreotide group from the open label extension of CLARINET.

\section{Quality of life utility values}

The utilities for patients with both stable and progressive disease were derived from a recent study that calculated health state utilities from Health Related Quality of Life Questionnaires administered to patients enrolled in the CLARINET trial [41]. These authors found a base case utility value of 0.79 for patients at time of enrollment and found a decrement in utility for patients whose disease progressed (Table 1). The decrement was greater in patients in the placebo arm.

Although carcinoid syndrome has been associated with lower health related quality of life scores, there are no published values for utilities for this health state [42]. Instead, we used utilities from patients with uncontrolled ulcerative colitis symptoms as a proxy, due to frequency of bowel movements and urgency symptoms being similar between the two groups, as was used in a recent cost-effectiveness analysis of telotristat for uncontrolled carcinoid symptoms $[42,43]$.

\section{Sensitivity analyses}

We conducted one-way deterministic sensitivity analyses and probabilistic sensitivity analysis (PSA) to examine the association of model parameter uncertainty on the modeling results. Sensitivity analyses included varying the costs, utilities and probabilities of progression of disease and probability of GEP-NETs related death (Table 1). For the PSA, we varied all parameter estimates simultaneously with gamma distribution for costs and beta distribution for utilities and probabilities. The PSA was run using Monte Carlo simulations with 100,000 iterations.

\section{Results}

Our base case modeling results showed that starting SSA immediately yielded the greatest life years and QALYs. The SSA strategy increased life expectancy by 0.62 years (7.5 months) but increased total costs by $\$ 170$, 455 , due to the longer duration of use of this costly monthly medication (Table 2). The unadjusted life-years with SSA was 4.41 years versus 3.78 years for the DELAY group. However, when accounting for quality of life, starting SSA promptly led to an improvement of 0.44 incremental QALYs. Compared to DELAY, the SSA strategy resulted in an ICER of $\$ 388,966$ and was not costeffective at our prescribed WTP threshold of $\$ 100,000$ per QALY. In the SSA arm, $94.1 \%$ of patients died due to GEP-NETs; in contrast, $94.9 \%$ of patients died due to GEP-NETs in the DELAY SSA arm.

The results of our one-way sensitivity analysis showed that the model was most sensitive to the cost of octreotide (Fig. 2). At a range of half to twice the current price, the ICER ranged from $\$ 240,517$ to $\$ 685,864$, all above the WTP threshold of $\$ 100,000$. To meet the WTP threshold of $\$ 100,000$, the cost of octreotide would have to fall to $\$ 110.09$. The model was also sensitive to changes in the baseline quality of life, probability of death due to GEP-NETs before starting SSA and the probability of progression of disease while on SSA. In contrast, the quality of life in the setting of uncontrolled diarrhea and risk of complications from SSA, both estimated to be low, did not significantly impact the model. There were no values where the ICER fell below $\$ 100,000$.

The PSA was run for 100,000 simulations. SSA strategy was only cost-effective $1.4 \%$ of the time at a WTP threshold of \$100,000 per QALY (Fig. 3).

\section{Discussion}

To our knowledge, this is the first cost-effectiveness model that examines when to initiate SSAs for patients with metastatic GEP-NETs. Both the European and American NET societies have issued consensus guidelines stating that initiation of SSAs is up to the treating clinician for patients who are asymptomatic [26, 27]. Our results suggest that although prompt initiation of SSA leads to a slight improvement in unadjusted life

Table 2 Results of Cost-effectiveness Analysis

\begin{tabular}{llllllll}
\hline Strategy & Cost & Incremental Cost & Un adjusted Life-years & Incremental LYs & QALYs & Incremental QALYs & ICER (\$/QALY) \\
\hline SSA & $\$ 606,397$ & $\$ 170,455$ & 4.41 & $0.62^{\text {a }}$ & 2.90 & 0.44 & $\$ 388,966$ \\
Delay SSA & $\$ 435,942$ & - & 3.78 & - & 2.46 & - & -
\end{tabular}

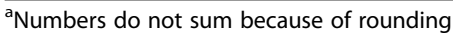

SSA somatostatin analogues; $L Y$ life years; $Q A L Y$ s quality-adjusted life years; ICER incremental cost-effectiveness ratio 


\section{Tornado Diagram - ICER SSA vs. DELAY}

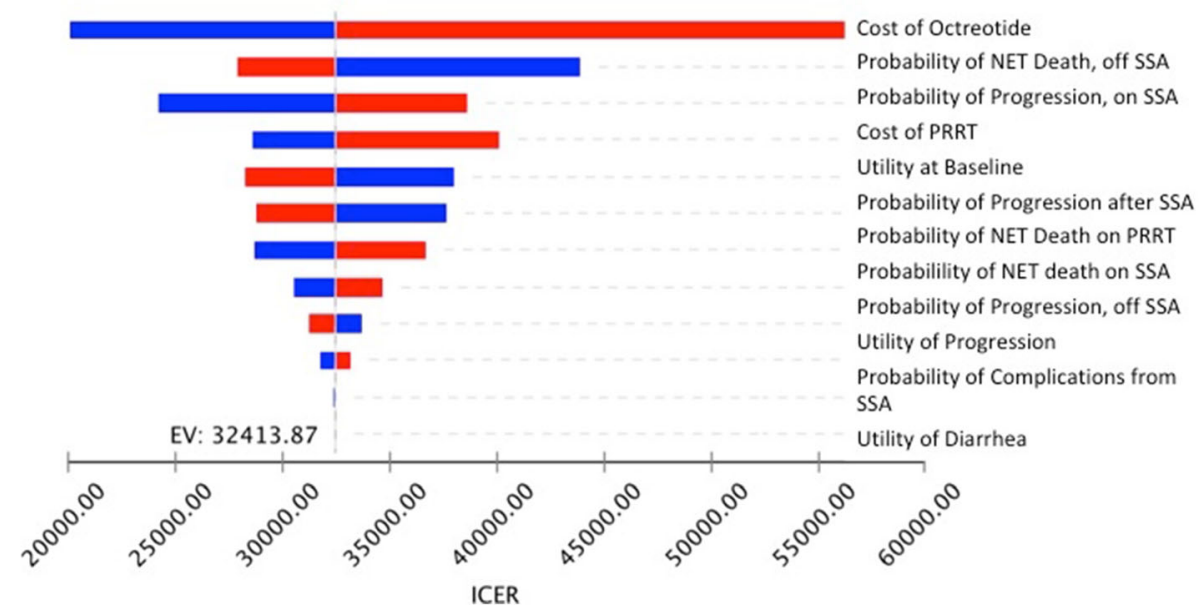

Fig. 2 Tornado Diagram - Incremental Cost-Effectiveness Ratio (ICER). The bars indicate the ICERs that result from the range of parameter inputs. NET = Neuroendocrine Tumor; SSA = somatostatin analogues; PRRT = Peptide Receptor Radionuclide Therapy; EV = expected value in base case

years, it is not cost effective when accounting for cost and quality of life.

Although two RCTs have suggested the use of SSA for patients with metastatic GEP-NET leads to delay in tumor progression [13] and improved progressionfree survival (PFS) [23], a net mortality benefit was not seen. In the CLARINET trial patients had been observed for 6 months prior to enrollment and had stable disease. A practitioner likely does not know whether the patients' disease is progressive or stable at the time of evaluation, and so the rates of progression from PROMID were used, where patients were enrolled without a period of observation. Given the expense and recruitment difficulties in conducting large clinical trials, it is unlikely there will be further multi-center RCTs to evaluate the use of SSAs for GEP-NET patients, and thus a microsimulation model may be useful to guide practitioners.

\section{CE Acceptability Curve}

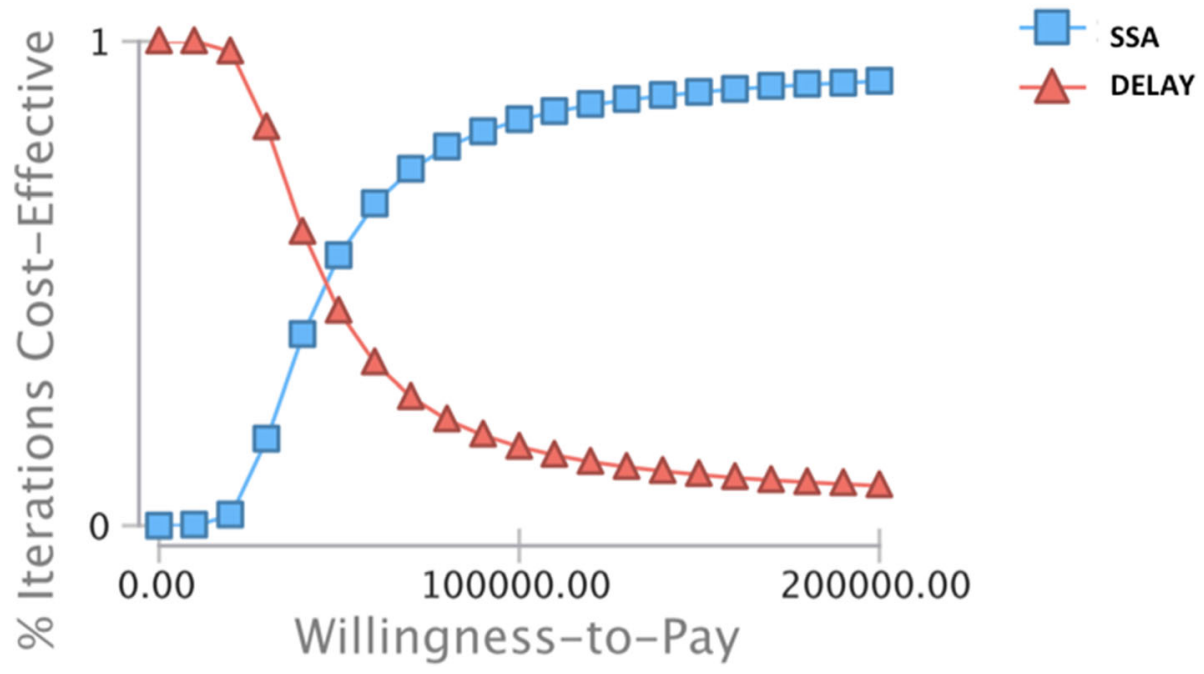

Fig. 3 Cost-Effectiveness Acceptability Curve. SSA = somatostatin analogues 
The two strategies in the model were similar, with the main difference being the point at which SSAs was initiated. Because the two strategies were almost identical after starting SSA, the factors that affected patients in the DELAY arm before initiating SSAs (the quality of life before progression of disease and the risk of death before progressing to start SSA) were the most significant factors differentiating the two arms. As discussed earlier, the tornado diagram depicts the factors to which the model is most sensitive (Fig. 2). The costs of the drug can vary widely internationally, and so these results using United States inputs may not be applicable to an international audience.

The results of our model confirm those found in the literature. The unadjusted survival of 4.41 years for the SSA arm is similar to that described in the SEER registry $[2,40]$. Although unadjusted life-years for the DELAY group was 3.78 years, this was more than described in SEER data but was plausible given the survival benefit of PRRT, a treatment available in both strategies in the model [44].

Cost-effectiveness models are an important tool to compare treatment costs and to account for the subsequent improvement in quality of life. They are best used as a guide at a societal level to account for benefits to patient care and costs to payors. Limitations of this model include that the two RCTs do not include information on NET-related death and had a selected patient population with low comorbid burdens, and so historical SEER data was used as a proxy. Another limitation is that we only included one medical treatment for patients in whom SSAs were inadequate to control their disease. Although other treatment options such as everolimus, surgery or embolization may be offered in clinical practice, we found no evidence that surgery has different outcomes depending on when SSAs were started, and thus the needs, costs and utilities were unlikely to be different between the two treatment arms and could be omitted from the model. Another limitation is the lack of utility values for quality of life for GEP-NET patients in various treatment stages, and so estimates from other disease states were used. This approximation has been used in other cost-effectiveness studies [42, 43]. However, it does not include approximations for flushing or carcinoid heart disease. Further clinical studies which identify patients most at risk for progression of disease may inform the model and identify a subpopulation in whom empiric initiation of SSA is cost-effective.

\section{Conclusion}

In conclusion, our study uses a well-established method to answer an important clinical question for practitioners caring for GEP-NET patients. Our model found that SSAs are effective and improve QALYS; however, because of the high cost of SSAs, it is not cost-effective to initiate SSA immediately for all patients with metastatic GEP-NETs. Further clinical studies are needed to confirm our findings and the optimal utilization of this drug.

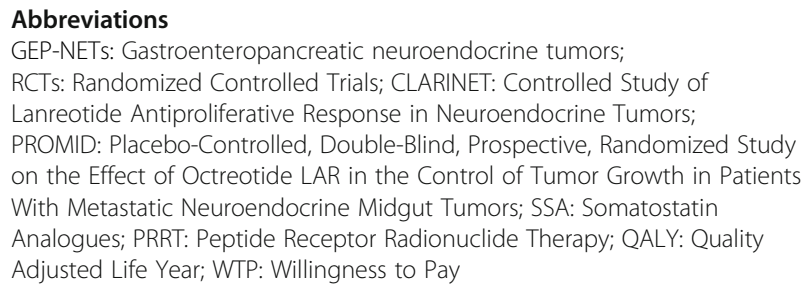

\section{Acknowledgements}

Not applicable.

\section{Authors' contributions}

All authors have read and approved the final manuscript. Data curation SDR, AO, JY, DK. Formal Analysis - SDR, AO, JY, DK. Conceptualization - EW, MKK, CH. Methodology - CH, AO. Supervision - EW, CH, MKK. Writing original draft - SDR, AO, JY. Writing - review and editing - SDR, AO, CYK, CH, MKK.

\section{Funding}

Chin Hur: R01CA212086; P30CA13696.

Michelle K. Kim: American Cancer Society grant MRSG-14-014-01-CCE.

The funding bodies had no role in the design of the study, data collection, data analysis, interpretation of data or writing of the manuscript.

Availability of data and materials

Not applicable.

\section{Declarations}

Ethics approval and consent to participate

Not applicable.

Consent for publication

Not applicable.

\section{Competing interests}

The authors declare they have no competing interests.

\section{Author details}

${ }^{1}$ Henry D. Janowitz Division of Gastroenterology, Mount Sinai Health System, Icahn School of Medicine at Mount Sinai, One Gustave L. Levy Place, Box 1118, New York, NY 10029-6574, USA. ²Columbia University Irving Cancer Center, Columbia University Medical Center, New York, NY, USA. ${ }^{3}$ Icahn School of Medicine at Mount Sinai, New York, NY, USA. ${ }^{4}$ Department of Internal Medicine, Lincoln Medical Center, Bronx, NY, USA. ${ }^{5}$ Division of Hematology and Oncology, Icahn School of Medicine at Mount Sinai, New York, NY, USA. ${ }^{6}$ Division of General Internal Medicine, Icahn School of Medicine at Mount Sinai, New York, NY, USA

Received: 1 March 2021 Accepted: 5 May 2021

Published online: 24 May 2021

\section{References}

1. Kunz PL. Understanding neuroendocrine tumors-a NET gain. JAMA Oncol. 2017;3(10):1343-4. https://doi.org/10.1001/jamaoncol.2017.0575.

2. Dasari A, Shen C, Halperin D, Zhao B, Zhou S, Xu Y, et al. Trends in the incidence, prevalence, and survival outcomes in patients with neuroendocrine tumors in the United States. JAMA Oncol. 2017;3(10):1335-42. https://doi.org/1 0.1001/jamaoncol.2017.0589.

3. Hallet J, Law CH, Cukier M, Saskin R, Liu N, Singh S. Exploring the rising incidence of neuroendocrine tumors: a population-based analysis of 
epidemiology, metastatic presentation, and outcomes. Cancer. 2015;121(4): 589-97. https://doi.org/10.1002/cncr.29099.

4. Lee MR, Harris C, Baeg KJ, Aronson A, Wisnivesky JP, Kim MK. Incidence Trends of Gastroenteropancreatic Neuroendocrine Tumors in the United States. Clin Gastroenterol Hepatol. 2019;17(11):2212-2217.e2211.

5. Fraenkel M, Kim M, Faggiano A, de Herder WW, Valk GD. Incidence of gastroenteropancreatic neuroendocrine tumours: a systematic review of the literature. Endocr Relat Cancer. 2014;21(3):R153-63. https://doi.org/10.1530/ ERC-13-0125.

6. Kim MK, Warner RRP, Roayaie S, Harpaz N, Ward SC, Itzkowitz S, et al. Revised staging classification improves outcome prediction for small intestinal neuroendocrine tumors. J Clin Oncol. 2013;31(30):3776-81. https:// doi.org/10.1200/JCO.2013.51.1477.

7. Chi W, Warner RRP, Chan DL, Singh S, Segelov E, Strosberg J, et al. Longterm outcomes of Gastroenteropancreatic neuroendocrine tumors. Pancreas. 2018;47(3):321-5. https://doi.org/10.1097/MPA.0000000000001005.

8. Lawrence B, Gustafsson BI, Chan A, Svejda B, Kidd M, Modlin IM. The epidemiology of gastroenteropancreatic neuroendocrine tumors. Endocrinol Metab Clin N Am. 2011;40(1):1-18, vii. https://doi.org/10.1016/j.ecl.2010.12. 005.

9. Darba J, Marsa A. Exploring the current status of neuroendocrine tumours: a population-based analysis of epidemiology, management and use of resources. BMC Cancer. 2019;19(1):1226. https://doi.org/10.1186/s12885-0196412-8.

10. Shen C, Dasari A, Gu D, Chu Y, Zhou S, Xu Y, et al. Costs of Cancer Care for Elderly Patients with neuroendocrine tumors. Pharmacoeconomics. 2018; 36(8):1005-13. https://doi.org/10.1007/s40273-018-0656-z.

11. Hallet J, Law CHL, Cheung M, Mittmann N, Liu N, Fischer HD, et al. Patterns and drivers of costs for neuroendocrine tumor care: a comparative population-based analysis. Ann Surg Oncol. 2017;24(11):3312-23. https://doi. org/10.1245/s10434-017-5986-0.

12. Mariotto $A B$, Yabroff KR, Shao Y, Feuer EJ, Brown ML. Projections of the cost of cancer care in the United States: 2010-2020. J Natl Cancer Inst. 2011; 103(2):117-28. https://doi.org/10.1093/jnci/djq495.

13. Rinke A, Muller HH, Schade-Brittinger C, et al. Placebo-controlled, doubleblind, prospective, randomized study on the effect of octreotide LAR in the control of tumor growth in patients with metastatic neuroendocrine midgut tumors: a report from the PROMID study group. J Clin Oncol. 2009; 27(28):4656-63. https://doi.org/10.1200/JCO.2009.22.8510.

14. Raymond E, Dahan L, Raoul JL, Bang YJ, Borbath I, Lombard-Bohas C, et al. Sunitinib malate for the treatment of pancreatic neuroendocrine tumors. N Engl J Med. 2011;364(6):501-13. https://doi.org/10.1056/NEJMoa1003825.

15. Yao JC, Shah MH, Ito T, Bohas CL, Wolin EM, van Cutsem E, et al. Everolimus for advanced pancreatic neuroendocrine tumors. N Engl J Med. 2011;364(6): 514-23. https://doi.org/10.1056/NEJMoa1009290.

16. Huynh L, Cai B, Cheng M, Lax A, Lejeune D, Duh MS, et al. Analysis of realworld treatment patterns, healthcare resource utilization, and costs between Octreotide and Lanreotide among patients with neuroendocrine tumors. Pancreas. 2019;48(9):1126-35. https://doi.org/10.1097/MPA.0000000000001403.

17. Chuang CC, Bhurke S, Chen SY, Brulais S, Gabriel S. Clinical characteristics, treatment patterns, and economic burden in patients treated for neuroendocrine tumors in the United States: a retrospective cohort study. J Med Econ. 2015;18(2):126-36. https://doi.org/10.3111/13696998.2014.975233.

18. Ayyagari R, Neary M, Li S, Rokito A, Yang H, Xie J, et al. Comparing the cost of treatment with Octreotide long-acting release versus Lanreotide in patients with metastatic gastrointestinal neuroendocrine tumors. Am Health Drug Benefits. 2017;10(8):408-15.

19. Oberg K, Kvols L, Caplin M, et al. Consensus report on the use of somatostatin analogs for the management of neuroendocrine tumors of the gastroenteropancreatic system. Ann Oncol. 2004;15(6):966-73. https:// doi.org/10.1093/annonc/mdh216.

20. Shen C, Shih YC, Xu Y, Yao JC. Octreotide long-acting repeatable use among elderly patients with carcinoid syndrome and survival outcomes: a population-based analysis. Cancer. 2014;120(13):2039-49. https://doi.org/10.1 002/cncr.28653.

21. Shen C, Shih YC, Xu Y, Yao JC. Octreotide long-acting repeatable among elderly patients with neuroendocrine tumors: a survival analysis of SEERMedicare data. Cancer Epidemiol Biomarkers Prevention. 2015;24(11):165665. https://doi.org/10.1158/1055-9965.EPI-15-0336.

22. Shen $C, X u$ Y, Dasari A, Shih YC, Yao JC. Octreotide LAR dosage and survival among elderly patients with distant-stage neuroendocrine tumors. Oncologist. 2016;21(3):308-13. https://doi.org/10.1634/ theoncologist.2015-0381.

23. Caplin ME, Pavel M, Cwikla JB, et al. Lanreotide in metastatic enteropancreatic neuroendocrine tumors. N Engl J Med. 2014;371(3):224-33. https://doi.org/10.1056/NEJMoa1316158.

24. Caplin ME, Pavel M, Cwikla JB, et al. Anti-tumour effects of lanreotide for pancreatic and intestinal neuroendocrine tumours: the CLARINET open-label extension study. Endocr Relat Cancer. 2016;23(3):191-9. https://doi.org/10.1 530/ERC-15-0490.

25. Rinke A, Wittenberg M, Schade-Brittinger C, Aminossadati B, Ronicke E, Gress TM, et al. Placebo-controlled, double-blind, prospective, randomized study on the effect of Octreotide LAR in the control of tumor growth in patients with metastatic neuroendocrine Midgut tumors (PROMID): results of long-term survival. Neuroendocrinology. 2017;104(1):26-32. https://doi. org/10.1159/000443612.

26. Pavel M, O'Toole D, Costa F, et al. ENETS consensus guidelines update for the Management of Distant Metastatic Disease of intestinal, pancreatic, bronchial neuroendocrine neoplasms (NEN) and NEN of unknown primary site. Neuroendocrinology. 2016;103(2):172-85. https://doi.org/10.1159/ 000443167.

27. Strosberg JR, Halfdanarson TR, Bellizzi AM, Chan JA, Dillon JS, Heaney AP, et al. The North American neuroendocrine tumor society consensus guidelines for surveillance and medical Management of Midgut Neuroendocrine Tumors. Pancreas. 2017;46(6):707-14. https://doi.org/10.1 097/MPA.0000000000000850.

28. Sandostatin LAR Prescribing Information. https://www.pharma.us.novartis. com/sites/www.pharma.us.novartis.com/files/sandostatin_lar.pdf. Updated April 2019. .

29. Somatuline prescribing information. 2014. https://www.accessdata.fda.gov/ drugsatfda_docs/label/2014/022074s011 lbl.pdf. Accessed 20 Mar 2020.

30. Strosberg J, Wolin E, Chasen B, Kulke M, Bushnell D, Caplin M, et al. Healthrelated quality of life in patients with progressive Midgut neuroendocrine tumors treated with (177)Lu-Dotatate in the phase III NETTER-1 trial. J Clin Oncol. 2018;36(25):2578-84. https://doi.org/10.1200/JCO.2018.78.5865.

31. North Carolina Medicaid DoHB. Lutetium Lu 177 Dotatate Injection, for Intravenous Use (Lutathera ${ }^{\oplus}$ ), HCPCS Code A9699: Billing Guidelines. https://medicaid.ncdhhs. gov/blog/2018/09/03/lutetium-lu-177-dotatate-injection-intravenous-uselutathera\%C2\%AE-hcpcs-code-a9699. Updated September 3, 2018.

32. Gabriel M, Nilica B, Kaiser B, Virgolini IJ. Twelve-year follow-up after peptide receptor radionuclide therapy. J Nucl Med. 2019;60(4):524-9. https://doi. org/10.2967/jnumed.118.215376.

33. Fisher GA Jr, Wolin EM, Liyanage N, Pitman Lowenthal S, Mirakhur B, Pommier RF, et al. Patient-reported symptom control of diarrhea and Flushing in patients with neuroendocrine tumors treated with Lanreotide depot/autogel: results from a randomized, placebo-controlled, double-blind and 32-week open-label study. Oncologist. 2018;23(1):16-24. https://doi. org/10.1634/theoncologist.2017-0284.

34. Marinova M, Mucke M, Fischer F, et al. Quality of life in patients with midgut NET following peptide receptor radionuclide therapy. Eur J Nucl Med Mol Imaging. 2019;46(11):2252-9. https://doi.org/10.1007/s00259-019-04431-3.

35. Services CfMM. April 2020 ASP Pricing File. https://www.cms.gov/medicare/ medicare-part-b-drug-average-sales-price/2020-asp-drug-pricing-files.

36. Valentim J, Passos V, Mataveli F, Calabro A. Cost-effectiveness analysis of somatostatin analogues in the treatment of acromegaly in Brazil. Arquivos Brasileiros de Endocrinologia e Metabologia. 2008;52(9):1452-60. https://doi. org/10.1590/S0004-27302008000900008.

37. Xuan JW, Zhang ZY, Wang YF, Mao ZG, Lu YJ, Wang RZ. Cost-effectiveness analysis of octreotide long acting release and lanreotide slow release for the treatment of postoperative patients with active acromegaly in China. Zhonghua Yi Xue Za Zhi. 2017;97(10):765-9. https://doi.org/10.3760/cma.j. issn.0376-2491.2017.10.010.

38. Buono S. Physics and medicine: the present and future of Theragnostics; 2018.

39. Arias E, Xu J. United States Life Tables, 2017. Hyattsville: National Center for Health Statistics; 2019.

40. Yao JC, Hassan M, Phan A, Dagohoy C, Leary C, Mares JE, et al. One hundred years after "carcinoid": epidemiology of and prognostic factors for neuroendocrine tumors in 35,825 cases in the United States. J Clin Oncol. 2008;26(18):3063-72. https://doi.org/10.1200/JCO.2007.15.4377.

41. Meng Y, McCarthy G, Berthon A, Dinet J. Patient-reported health state utilities in metastatic gastroenteropancreatic neuroendocrine tumours - an 
analysis based on the CLARINET study. Health Qual Life Outcomes. 2017; 15(1):131. https://doi.org/10.1186/s12955-017-0711-z.

42. Joish VN, Frech F, Lapuerta P. Cost-effectiveness analysis of telotristat ethyl for treatment of carcinoid syndrome diarrhea inadequately controlled with somatostatin analogs. J Med Econ. 2018;21(2):182-8. https://doi.org/10.1 080/13696998.2017.1387120.

43. Arseneau KO, Sultan S, Provenzale DT, Onken J, Bickston SJ, Foley E, et al. Do patient preferences influence decisions on treatment for patients with steroid-refractory ulcerative colitis? Clin Gastroenterol Hepatol. 2006;4(9): 1135-42. https://doi.org/10.1016/j.cgh.2006.05.003.

44. Strosberg J, El-Haddad G, Wolin E, et al. Phase 3 trial of 177Lu-Dotatate for Midgut neuroendocrine tumors. N Engl J Med. 2017;376(2):125-35. https:// doi.org/10.1056/NEJMoa1607427.

\section{Publisher's Note}

Springer Nature remains neutral with regard to jurisdictional claims in published maps and institutional affiliations.

Ready to submit your research? Choose BMC and benefit from:

- fast, convenient online submission

- thorough peer review by experienced researchers in your field

- rapid publication on acceptance

- support for research data, including large and complex data types

- gold Open Access which fosters wider collaboration and increased citations

- maximum visibility for your research: over $100 \mathrm{M}$ website views per year

At BMC, research is always in progress.

Learn more biomedcentral.com/submissions 